\title{
Modification of glassy carbon surfaces by atmospheric pressure cold plasma torch
}

Mortensen, Henrik Junge; Kusano, Yukihiro; Leipold, Frank; Rozlosnik, Noemi; Kingshott, Peter; Goutianos, Stergios; Sørensen, Bent F.; Stenum, Bjarne; Bindslev, Henrik

Published in:

Japanese Journal of Applied Physics

Link to article, DOI:

10.1143/JJAP.45.8506

Publication date:

2006

Document Version

Publisher's PDF, also known as Version of record

Link back to DTU Orbit

Citation (APA):

Mortensen, H. J., Kusano, Y., Leipold, F., Rozlosnik, N., Kingshott, P., Goutianos, S., Sørensen, B. F., Stenum, B., \& Bindslev, H. (2006). Modification of glassy carbon surfaces by atmospheric pressure cold plasma torch. Japanese Journal of Applied Physics, 45(10 B), 8506-8511. https://doi.org/10.1143/JJAP.45.8506

\section{General rights}

Copyright and moral rights for the publications made accessible in the public portal are retained by the authors and/or other copyright owners and it is a condition of accessing publications that users recognise and abide by the legal requirements associated with these rights.

- Users may download and print one copy of any publication from the public portal for the purpose of private study or research.

- You may not further distribute the material or use it for any profit-making activity or commercial gain

- You may freely distribute the URL identifying the publication in the public portal 
(C) 2006 The Japan Society of Applied Physics

\title{
Modification of Glassy Carbon Surfaces by Atmospheric Pressure Cold Plasma Torch
}

\author{
Henrik Mortensen*, Yukihiro Kusano, Frank Leipold, Noemi RozlosniK ${ }^{1}$, Peter Kingshott ${ }^{1}$, \\ Stergios Goutianos ${ }^{2}$, Bent F. SøRENSEN ${ }^{2}$, Bjarne Stenum and Henrik BindSLeV \\ Optics and Plasma Research Department, Ris $\phi$ National Laboratory, Frederiksborgvej 399, P.O. Box 49, DK-4000 Roskilde, Denmark \\ ${ }^{1}$ Danish Polymer Centre, Risф National Laboratory, Frederiksborgvej 399, P.O. Box 49, DK-4000 Roskilde, Denmark \\ ${ }^{2}$ Materials Research Department, Ris $\phi$ National Laboratory, Frederiksborgvej 399, P.O. Box 49, DK-4000 Roskilde, Denmark
}

(Received January 24, 2006; accepted May 15, 2006; published online October 24, 2006)

The effect of plasma treatment on glassy carbon (GC) surfaces was studied with adhesion improvement in mind. A newly constructed remote plasma source was used to treat GC plates. Pure He and a dilute $\mathrm{NH}_{3} / \mathrm{He}$ mixture were used as feed gases. Optical emission spectroscopy was performed for plasma torch diagnostics. The treatment resulted in surface etching, substantially enhanced by $\mathrm{NH}_{3}$, as well as a roughening of the surface as measured by atomic force microscopy. Furthermore, the treated area showed an increased wettability indicating the addition of polar functional groups to the surface. X-ray photoelectron spectroscopy confirmed the introduction of several oxygen and nitrogen containing surface functional groups. The adhesion to epoxy was dramatically improved after exposure to either plasma, the effect being largest when $\mathrm{NH}_{3}$ was present in the feed gas. [DOI: 10.1143/JJAP.45.8506]

KEYWORDS: glassy carbon, atmospheric pressure, plasma, adhesion, etching, surface treatment, optical emission spectroscopy, ammonia, helium, dielectric barrier discharge

\section{Introduction}

Glassy carbon (GC) is a disordered polymer-like, nongraphitizing form of $\mathrm{sp}^{2}$-hybridized elemental carbon. GC plates are structurally and chemically similar to carbon fibres, but easier to handle. They are thus ideal model specimens for fundamental studies on the adhesion phenomena resulting from various surface treatments aimed at increasing the strength of carbon fibre reinforced composite materials.

In order to form a strong and durable adhesive bond between any two objects, e.g., a fibre and the matrix in a composite material, pretreatment of the surfaces is often necessary. Various methods are employed, such as wet chemical or low-pressure plasma processes. However, atmospheric pressure plasma treatment generally presents distinct environmental and/or economical advantages. Recent experimental evidence ${ }^{1)}$ shows that atmospheric pressure plasmas can indeed be used to increase the strength of fibre/matrix adhesion in carbon fibre composites.

We have studied the effect of surface treating GC plates on the adhesion of the GC to epoxy resin using cold plasmas generated at atmospheric pressure in a torch-like source.

The strength of adhesion to epoxy is expected to depend mainly on surface roughness and on the presence of surface polar functional groups, in particular amino groups $\left(\mathrm{NH}_{2}\right)$. Since ammonia $\left(\mathrm{NH}_{3}\right)$ plasmas are known to promote roughening $^{2)}$ and can act as a source of amino and other nitrogen containing functional groups (see ref. 3 and references therein), we compare the effect of a plasma of $\mathrm{NH}_{3}$ diluted in $\mathrm{He}$ with that of a plasma generated in a flow of pure He. Optical emission spectra (OES) are presented for the two types of plasma. In addition, microscopic and profilometric measurements show microscopic roughening and etching of the surface, and evidence of the chemical modifications is determined by water contact angles and Xray photoelectron spectroscopy (XPS). Finally, the effect on adhesion is presented.

*E-mail address: Henrik.Junge.Mortensen@Risoe.dk

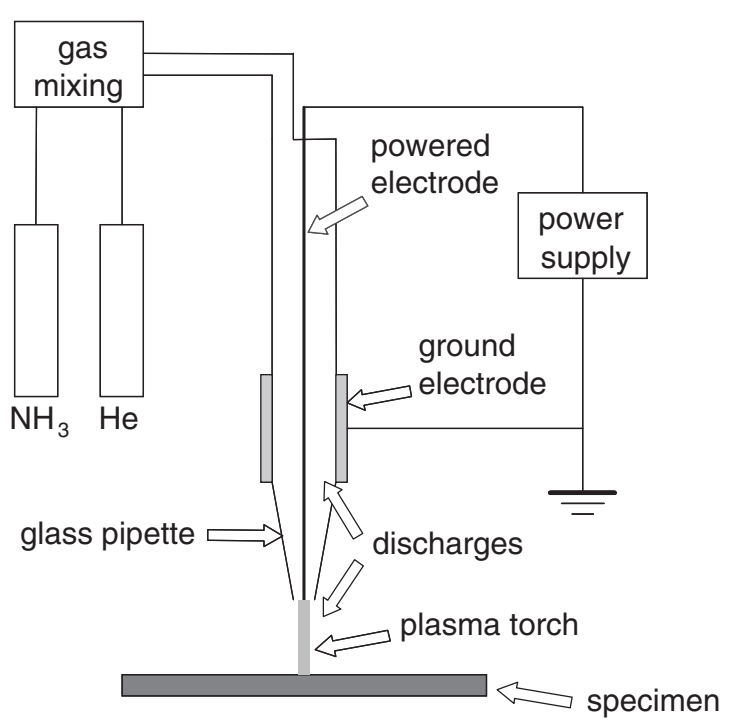

Fig. 1. Schematic of our experimental setup for cold atmospheric pressure plasma torch treatment of a glassy carbon surface.

\section{Experiment}

The torch is based on the design by Koinuma et al. ${ }^{4)}$ and is operated in a ventilated box at atmospheric pressure. Figure 1 shows a schematic of the setup. The powered electrode is a 0.5 -mm diameter tungsten wire placed inside a glass pipette, which serves as the dielectric barrier. The inner and outer diameters of the pipette are 5.5 and $7 \mathrm{~mm}$, respectively, tapering to approximately 1.5 and $2.2 \mathrm{~mm}$ at the plasma outlet. Wrapped around the glass tube a strip of $\mathrm{Al}$ foil constitutes the ground electrode. It is connected to ground through a 50-ohm non-inductive high power resistor to facilitate measurement of the dielectric barrier discharge current. The discharge voltage and current were recorded by a digital oscilloscope which was also used to calculate the corresponding power dissipation. The total power dissipated in the torch cannot be measured directly, but we find it fair to 


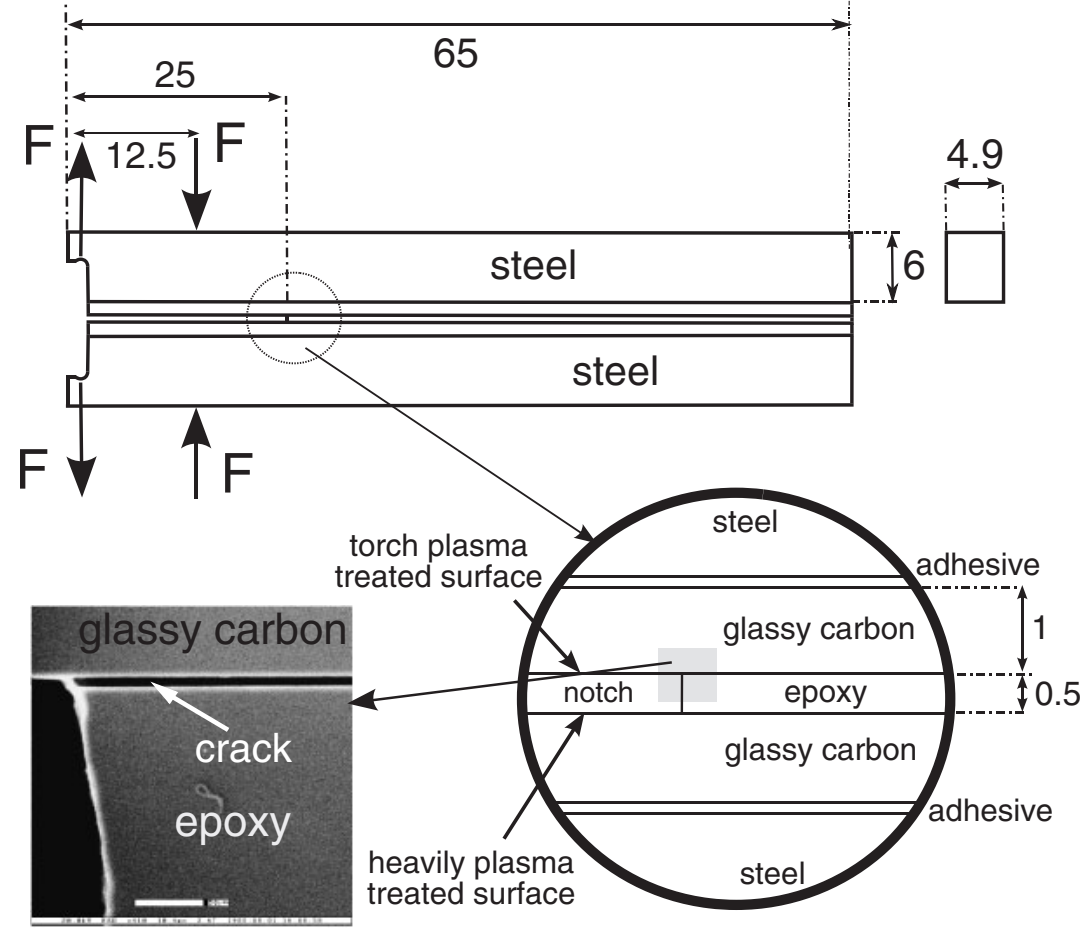

Fig. 2. Schematic of a DCB sandwich specimen. The crack formed along the interface upon loading is indicated in the image. "F" indicates the symmetrically applied forces. Dimensions in $\mathrm{mm}$. assume that it is within the same order of magnitude as our measured power.

Prior to plasma exposure the polished GC plates $(65 \times$ $5 \times 1 \mathrm{~mm}^{3}$ Sigradur-G, HTW Hochtemperatur-Werkstoffe) were cleaned by wiping with acetone. Samples for XPS analysis were cleaned ultrasonically for $5 \mathrm{~min}$ in dichloromethane followed by twice $5 \mathrm{~min}$ in acetone and finally $5 \mathrm{~min}$ in methanol.

The plasmas were generated by applying an ac voltage (typically $4 \mathrm{kV}_{\mathrm{p}-\mathrm{p}}$ at $14 \mathrm{kHz}$ ) between the electrodes in a flow of $31 / \mathrm{min}(\sim 28 \mathrm{~m} / \mathrm{s})$ of He pure or premixed with $5 \mathrm{ml} / \mathrm{min}$ of $\mathrm{NH}_{3}$. The measured power was around $1 \mathrm{~W}$. During plasma treatment, the samples were electrically isolated. A stable glow was observed between the pipette wall and the powered electrode as well as in the 5-mm gap between the torch orifice and the substrate. The light emitted by the effluent plasma was focussed by a quartz lens onto a spectrometer grating with 3600 grooves $/ \mathrm{mm}$ (for wavelengths $\lambda<400 \mathrm{~nm})$ or 1200 grooves $/ \mathrm{mm}(\lambda>400 \mathrm{~nm})$, and OES were captured by means of a charge-coupled device (CCD) camera.

Contact angles with deionized water were measured both before and after the plasma treatment to evaluate the change in surface wettability. The induced microscopic roughness of the surfaces was evaluated by intermittent contact atomic force microscopy (AFM; XE-150, PSIA). For estimating the etch rate we used a stylus profilometer (Dektak V200-Si, Veeco Instruments) with a 700-nm diameter stylus to record height profiles across treated spots on the surface.

Chemical analysis of the GC surfaces was performed using an XPS system (Sage 100, SPECS) operated at a pressure of $<10^{-5} \mathrm{~Pa}$. All samples were analyzed using an unmonochromated $\mathrm{Mg} K \alpha \mathrm{X}$-ray source operated at a power of $300 \mathrm{~W}$ at a take-off angle of $90^{\circ}$, resulting in a maximum probe depth of $\approx 10 \mathrm{~nm}$. The number of scans was minimized in order to prevent X-ray induced sample damage, and kept constant for all the samples. Atomic concentrations of each element were calculated by determining the relevant integral peak intensities using a linear background. The systematic error is estimated to be in the order of 5-10\%. Regional analysis was performed on the carbon 1s (C 1s), nitrogen 1s (N 1s), and oxygen 1s (O 1s) (pass energy $23 \mathrm{eV}$ ). The spectra were deconvoluted through curve-fitting. The technique employs $100 \%$ Gaussian components and linear background subtraction that relies on a least squares minimization routine. The binding energies were corrected by referring to the hydrocarbon component $\left(\mathrm{C}-\mathrm{C} / \mathrm{C}-\mathrm{H}_{x}\right)$ at $285.0 \mathrm{eV}$. ${ }^{5}$

A simple adhesion test was applied for the preliminary evaluation of the effect of the plasma treatment on adhesion with epoxy. A $\sim 1.5 \mathrm{~mm}$ thick layer of epoxy (Strong Epoxy Rapid 2806, Casco) was applied to one side of the samples and cured at $100^{\circ} \mathrm{C}$ for 60 minutes. Delamination was then attempted by trying to insert a blade at the interface between the GC surface and the cured epoxy.

For quantitative measurements of the strength of adhesion of epoxy to the treated surfaces, double cantilever beam (DCB) sandwich specimens produced with the glassy carbon plates were tested under the application of pure bending moments. A sketch of the DCB sandwich specimens is presented in Fig. 2. They were prepared as follows: The GC plate was placed in a silicone mould, its treated surface facing another, heavily plasma treated GC plate. $0.5 \mathrm{~mm}$ thick Teflon inserts were placed at each end of the zone to be bonded, ensuring a uniform adhesive thickness. The uncured epoxy resin (Prime 20, SP Systems) fluid was mixed with the hardener (diethylenetriamine/polyoxypropylamine) at a ratio $4: 1$ and degassed under vacuum for $2 \times 15 \mathrm{~min}$ to remove air bubbles before being introduced between the inserts. The specimens were left in the mould for at least a day at room temperature and for $16 \mathrm{~h}$ at $50{ }^{\circ} \mathrm{C}$ for curing the epoxy resin. Two $6 \mathrm{~mm}$ thick steel beams were glued to the 
outsides of the sandwich structure with an epoxy adhesive (Scotch Weld) to support the glassy carbon. The curing time was $24 \mathrm{~h}$ at room temperature. With the steel beams attached, the test specimens fit the testing fixture, which was placed under an optical microscope for observation of crack growth. Pure bending moments were applied to the DCB sandwich specimens by a loading arrangement with wires and special grips.6) In successful experiments, the loading would cause the initiation and growth of a crack at the interface between the central layer of epoxy and the GC plate under investigation. During the test, the moment was recorded along with the opening of the cracked end of the specimen. An acoustic emission sensor taped to the specimen aided our visual detection of crack growth events and thus allowed us to record for each specimen several load/ unload cycles each associated with crack growth. The corresponding fracture energy was calculated as the critical energy release ${ }^{7)}$ using the highest moments applied during the last few cycles before failure. For this calculation the effect of resins is ignored, since their stiffness is much smaller compared to the glassy carbon plates and the steel beams.

Samples for contact angle and AFM measurements and for adhesion tests were prepared for each gas composition with a total exposure time of 1 and 5 min during which the sample was manually moved continuously to achieve a quasi-homogeneous exposure of the surface in the $\sim 100$ $\mathrm{mm}^{2}$ zone between $\sim 32$ and $52 \mathrm{~mm}$ from one end of the sample. For measurements of the etch rate, one sample per gas composition was prepared by stationary exposure to the plasma in three separate areas, which were exposed for 3, 30, and $300 \mathrm{~s}$, respectively. The spots with a 3-s treatment time were characterized by AFM prior to the profilometry. Both types of treatment procedures were employed for XPS samples.

\section{Results and Discussion}

If the plasma etches or erodes the glassy carbon surface then the plasma above the surface can be expected to contain a substantial amount of electronically excited carbonaceous species. Yamagata et al. ${ }^{8,9)}$ used OES to detect such species in the plasma plumes resulting from laser ablation from various other elemental carbon surfaces. We recorded OES of the torch plasmas covering the range of wavelengths between 187 and $800 \mathrm{~nm}$.

The dominant features in the spectra are due to $\mathrm{N}_{2}$ * $\left(C^{3} \Pi_{u}-B^{3} \Pi_{g}\right), \mathrm{N}_{2}{ }^{+}\left(B^{2} \Sigma_{u}^{+}-X^{2} \Sigma_{g}^{+}\right)$, and He I. No signatures of carbonaceous species could be identified in the spectra, which did not depend on the distance from the substrate surface to the probed volume.

As can be seen from Fig. 3(a), a comparison of the emission from the $\mathrm{NH}_{3} / \mathrm{He}$ discharge with that from the $\mathrm{He}$ one revealed that the $\mathrm{NH}_{3}$ resulted in a substantially more intense $\mathrm{NH}\left(c^{1} \Pi-a^{1} \Delta\right)(0,0)$ band at $324 \mathrm{~nm}$ and additional bands around $336-337 \mathrm{~nm}$ that may in part be attributed to the $\mathrm{NH}\left(A^{3} \Pi-X^{3} \Sigma\right)(0,0)$ and $(1,1)$ transitions. By contrast, $\mathrm{O}$ I lines and the $\mathrm{OH}(A-X)(0,0)$ band at $306.4 \mathrm{~nm}$ [see Fig. 3(b)] were much more intense in the pure He discharge spectra, which also displayed a higher ratio of the intensity from $\mathrm{N}_{2}{ }^{+}$ions to that from $\mathrm{N}_{2}{ }^{*}$ neutrals [see Fig. 3(c)].

The quasi-uniformly treated samples, the spots created by
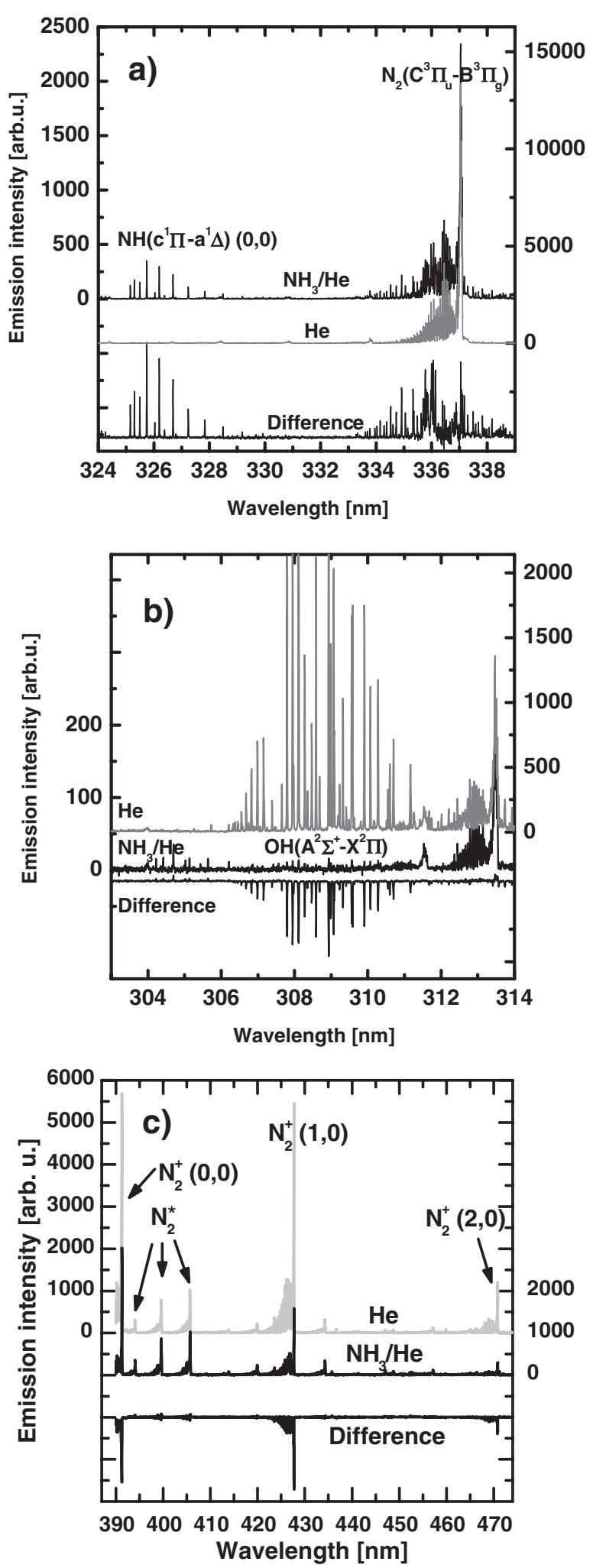

Fig. 3. Features from the $\mathrm{OES}$ of the $\mathrm{He}$ and $\mathrm{NH}_{3} / \mathrm{He}$ torch plasmas as well as their difference: (a) the NH bands around 324 and $336 \mathrm{~nm}$, (b) the $3064 \AA$ system of $\mathrm{OH}$, and (c) bands of the second positive and first negative systems of $\mathrm{N}_{2}{ }^{*}$ and $\mathrm{N}_{2}{ }^{+}$, respectively. In the difference spectra, negative peaks represent species dominant in the He plasma; positive peaks species dominant in the $\mathrm{NH}_{3} / \mathrm{He}$ plasma. All spectra have been rescaled to equalize the $\mathrm{N}_{2}{ }^{*}$ bands.

3-s stationary treatment, and a cleaned, but untreated sample were imaged by AFM. The He plasma treated samples could be readily imaged in intermittent contact mode, whereas 

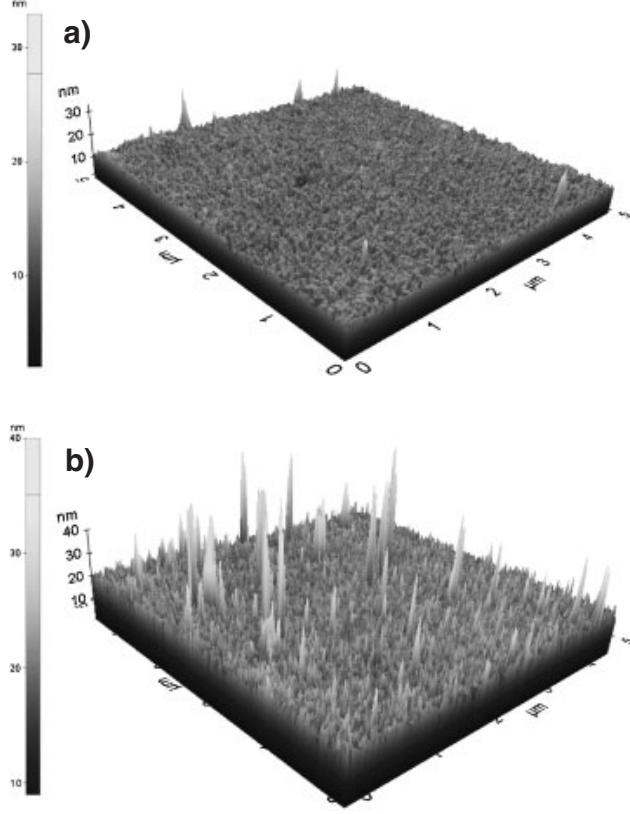

Fig. 4. $5 \times 5 \mu \mathrm{m}^{2}$ intermittent contact AFM micrographs of the GC surface (a) untreated, and (b) after exposure to He plasma for approximately $2 \mathrm{~s}\left(5 \mathrm{~min}\right.$ total treatment time of $100 \mathrm{~mm}^{2}$ with a torch of 1-mm diameter).

neither intermittent contact nor contact mode enabled stable imaging of the samples treated by the $\mathrm{NH}_{3} / \mathrm{He}$ plasma. We tentatively attribute this behaviour to patches of electrical charge on the surface possibly due to deposition from the plasma, but further studies are required in order to determine the true cause of the unstable imaging. Examples of images obtained on the untreated surface vs a He plasma treated surface are shown in Fig. 4.

The difference is immediately apparent. All images were flattened (offset) line by line to allow a meaningful evaluation of the roughness. The average root mean square roughness $\left(r_{\mathrm{q}}\right)$ measured on the untreated surface was $1.3 \mathrm{~nm}$, whereas on the He plasma treated samples it was similar for the 1-min quasi-uniform treatment, $3.3 \mathrm{~nm}$ for the 5-min, and $2.2 \mathrm{~nm}$ for the 3 -s spot treatments. As Fig. 4 suggests, the increase of the $r_{\mathrm{q}}$-values is composed of a small, relatively uniform roughening and an additional appearance of randomly, but less uniformly and rather sparsely distributed protrusions ("bumps") with an apparent height of up to $50 \mathrm{~nm}$. Both will naturally increase the effective surface area, but the effect of the "bumps" on the strength of an adhesive joint is uncertain, as their chemical composition as well as their cohesive and adhesive properties are undetermined thus far.

Several adjacent traces were measured with the profilometer across each area exposed in the stationary mode. The volume of material removed from each area was estimated by selecting from each set of such measured profiles the one displaying the deepest depression and integrating it over $180^{\circ}$ around its centre axis, thus assuming an axisymmetric hole. The results are summarized in Table I.

The data are consistent with a constant etch rate for each plasma throughout the 300-s maximum treatment. Visually, the $\mathrm{NH}_{3} / \mathrm{He}$ treated samples appeared somewhat more discoloured, and ammonia is found to remarkably promote
Table I. Estimated plasma etched volumes $(V)$ in $\mu \mathrm{m}^{3}$ and maximum depths $(d)$ in $\mu \mathrm{m}$.

\begin{tabular}{cccccc}
\hline \multirow{2}{*}{$\begin{array}{c}\text { Exposure time } \\
(\mathrm{s})\end{array}$} & \multicolumn{2}{c}{$\mathrm{He}$} & & \multicolumn{2}{c}{$\mathrm{NH}_{3} / \mathrm{He}$} \\
\cline { 2 - 3 } \cline { 5 - 6 } 3 & & & & \\
\hline 30 & $3.9 \times 10^{4}$ & 0.27 & & $0.5 \times 10^{4}$ & 0.18 \\
300 & $3.7 \times 10^{5}$ & 2.3 & & $5.5 \times 10^{6}$ & 9.2 \\
\hline
\end{tabular}

Table II. Elemental composition of the glassy carbon surfaces as derived from XPS.

\begin{tabular}{lrrrc}
\hline \multicolumn{1}{c}{ Treatment } & $\% \mathrm{C}$ & $\% \mathrm{O}$ & $\% \mathrm{~N}$ & $\% \mathrm{Si}$ \\
\hline Untreated & 96.8 & 3.2 & - & - \\
$\mathrm{He} 300 \mathrm{~s}$ & 77.9 & 18.1 & 2.6 & 1.4 \\
$\mathrm{NH}_{3} / \mathrm{He} 300 \mathrm{~s}$ & 77.5 & 14.7 & 5.4 & 2.3 \\
$\mathrm{He} 300-\mathrm{s} \mathrm{spot}$ & 72.4 & 23.3 & 0.9 & 3.4 \\
$\mathrm{NH}_{3} / \mathrm{He} 300-\mathrm{s} \mathrm{spot}$ & 91.4 & 6.7 & 1.0 & 1.0 \\
\hline
\end{tabular}

etching. The $\mathrm{NH}_{3} / \mathrm{He}$ mixture etched approximately $2 \times 10^{4} \mu \mathrm{m}^{3} / \mathrm{s}$ compared to the $1.2 \times 10^{3} \mu \mathrm{m}^{3} / \mathrm{s}$ of the pure He plasma.

It is interesting to compare the above data to standard lowpressure reactive ion etching (RIE) techniques applied for microstructuring surfaces. Kuhnke et al. have recently applied low-pressure RIE to the micromachining of glassy carbon electrodes for micro fuel cells with potential applications in portable electronics. ${ }^{10,11)}$ Employing an $\mathrm{rf}$ oxygen plasma, they reported a maximum etch rate of $40 \mu \mathrm{m} / \mathrm{h}$ and an efficiency of $\sim 10^{6} \mu \mathrm{m}^{3} / \mathrm{s}$ per $\mathrm{W}$ of rf power with a substrate bias of $800 \mathrm{~V}$ at $13 \mathrm{~Pa}(100 \mathrm{mT}$ Torr $)$ pressure. In our case of the atmospheric pressure $\mathrm{NH}_{3} / \mathrm{He}$ plasma the corresponding parameters are $110 \mu \mathrm{m} / \mathrm{h}$ and $2 \times 10^{4} \mu^{3}$ $\mathrm{s}^{-1} \mathrm{~W}^{-1}$, respectively, for an unbiased substrate. The plasma torch thus etches slightly faster perpendicular to the surface, but acts very locally and (assuming that no other power than that supplied at rf to maintain the plasma is acting in the low-pressure setup) with a relatively poor energy efficiency compared to low-pressure RIE systems.

The water contact angle $(\theta)$ on untreated GC is $\sim 97^{\circ}$. On the treated samples, the angles were first measured approximately $30 \mathrm{~min}$ after treatment. All of the four samples (two gas compositions, 1 and 5 min total treatment) were highly hydrophilic with $\theta$ too small to be measured. The same was true $100 \mathrm{~min}$ after treatment. After $170 \mathrm{~min}$, the He plasma treated samples displayed $\theta \sim 5-10^{\circ}$, whereas the $\mathrm{NH}_{3} / \mathrm{He}$ plasma treated ones had $\theta \sim 12-24^{\circ}$, still significantly lower than the untreated sample. The aging mechanism has not yet been studied, but our previous experiments with plasma treated GC show that a residual effect remains even after 3 months of storage under ambient conditions.

With the above aging effect in mind, care was taken to perform XPS analysis as soon as possible after plasma treatment. All samples were transferred to high vacuum within 95 min after treatment, and XPS measurements were initiated immediately thereafter.

In Table II the elemental compositions derived from XPS of two uniformly treated, two spot treated, and one untreated sample are given. It is clear that the plasma treatment 
Table III. Binding energies (BE) and weights (\%) of the components of the XPS peaks from C 1s (A-H), O 1s (I-L), and N 1s (M-O). Our assignment of the $\mathrm{C} 1 \mathrm{~s}$ peaks is as follows: ${ }^{5)} \mathrm{A}: \mathrm{C}-\mathrm{H}, \mathrm{C}-\mathrm{C}$, or $\mathrm{C}=\mathrm{C}$; $\mathrm{B}$ : $\mathrm{C}-\mathrm{OH}, \mathrm{C}-\mathrm{O}-\mathrm{C}$, or $\mathrm{C}-\mathrm{N}$; $\mathrm{C}$ : C=O or O-C-O; D: acid or ester; E-H: aromatic carbon $\left(\pi-\pi^{*}\right.$ satellite peaks). For the assignment of $\mathrm{O} 1 \mathrm{~s}$ and $\mathrm{N} 1 \mathrm{~s}$, the reader is referred to the text.

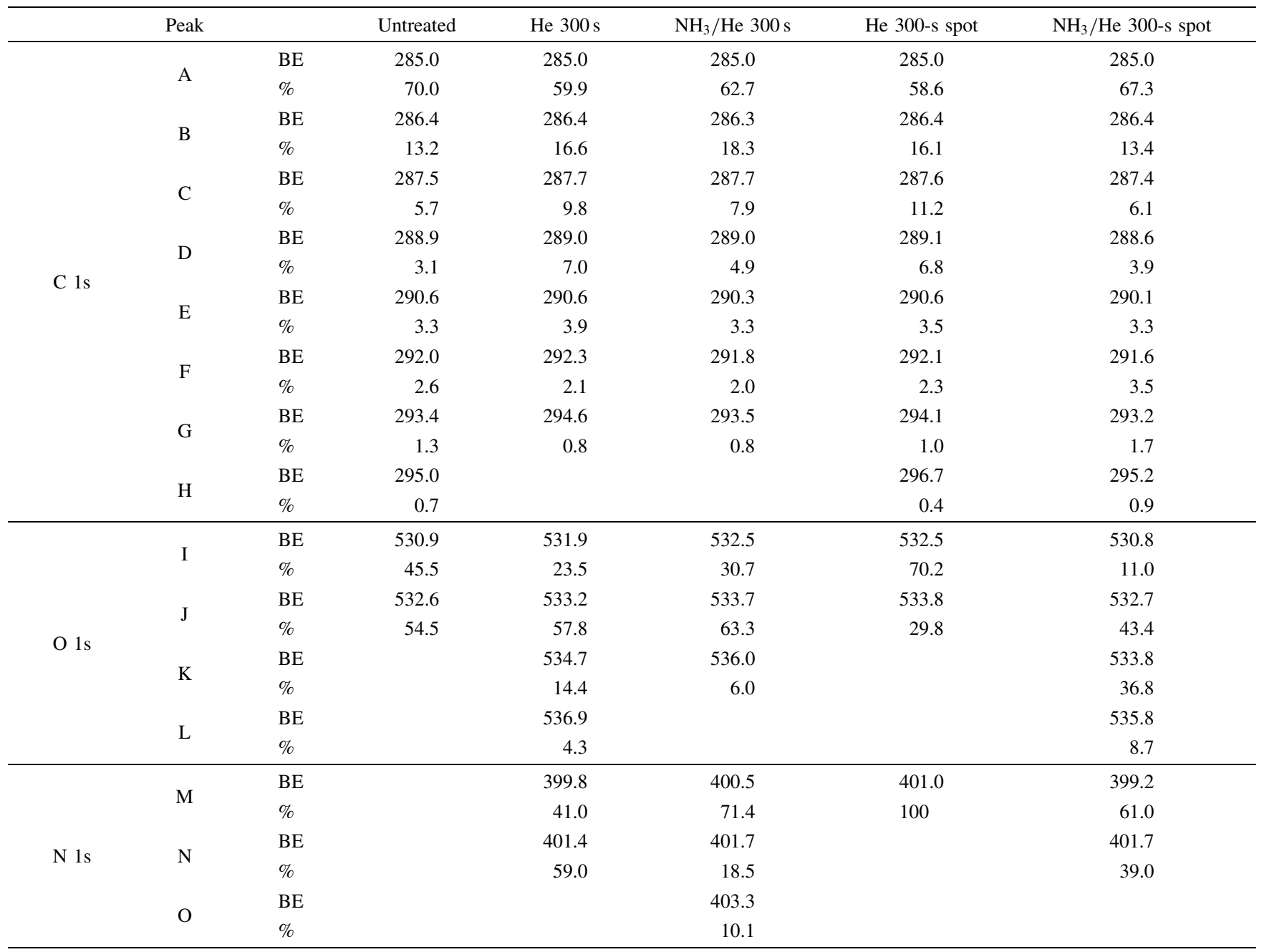

strongly increases the surface contents of oxygen and nitrogen, as expected. A slight predominance of oxygen or of nitrogen is observed with $\mathrm{He}$ or $\mathrm{NH}_{3} / \mathrm{He}$ plasma treatment, respectively. In addition, the treated samples contain some surface silicon, most likely eroded from the glass pipette.

Additional information on the oxygen and nitrogen containing functional groups is obtained from the peak shape analysis of the $1 \mathrm{~s}$ peaks of $\mathrm{C}, \mathrm{N}$, and $\mathrm{O} .{ }^{5)}$ The results of this analysis are summarized in Table III. In addition to the main hydrocarbon peak at $285.0 \mathrm{eV}$, components at higher binding energies up to $296.7 \mathrm{eV}$ appear in the $\mathrm{C} 1 \mathrm{~s}$ signal. All treatments give rise to an increase in the components corresponding to $\mathrm{C}-\mathrm{OH}, \mathrm{C}-\mathrm{O}-\mathrm{C}$, or $\mathrm{C}-\mathrm{N}$ $(\sim 286.4 \mathrm{eV})$ and $\mathrm{C}=\mathrm{O}$ or $\mathrm{O}-\mathrm{C}-\mathrm{O}(\sim 287.5 \mathrm{eV})$, whereas the component that could be due to acid or ester groups $(\sim 289.0 \mathrm{eV})$ is enhanced mainly by the pure He plasma. The $\mathrm{O} 1 \mathrm{~s}$ peaks after plasma treatment primarily consist of components with binding energies in the range of 531.9$533.8 \mathrm{eV}$, which can be assigned to ${ }^{*} \mathrm{O}=\mathrm{C}-\mathrm{O}, \mathrm{O}=\mathrm{C}-\mathrm{O}^{*}$, ${ }^{5)}$ or $\mathrm{C}-\mathrm{O}$ groups. ${ }^{12)}$ The lowest energy $(\sim 530.8 \mathrm{eV})$ components could be due to $\mathrm{C}=\mathrm{O},{ }^{13}$ ) whereas the highest energy components might be attributed to adsorbed $\mathrm{H}_{2} \mathrm{O}$ or $\mathrm{O}_{2} .{ }^{14)}$ There are, however, several possible fits to the $\mathrm{O} 1 \mathrm{~s}$ data, so the binding energies and weights stated in the table should only be regarded as a relatively rough indication of the peak shape. Similarly, due to the low N content, any assignment of $\mathrm{N}$ containing functional groups will be rather uncertain. The $\mathrm{N}$ 1s peak shapes observed are consistent with a mixture of $\mathrm{C}-\mathrm{C}=\mathrm{O}(\mathrm{N}), \mathrm{C}=\mathrm{O}(\mathrm{N}) \mathrm{C}=\mathrm{O}$, or amide $(399.8-400.6 \mathrm{eV})^{5)}$ along with possibly $\mathrm{NH}_{3}{ }^{+}(401.5 \mathrm{eV}), \mathrm{N}-\mathrm{H}(400.2 \mathrm{eV})$, and $\mathrm{N}-\mathrm{H} \cdots \mathrm{O}(399.3 \mathrm{eV}) .^{15)}$

In conclusion, the predominant modifications of the surface are likely to be the production of carboxylic acid, ester, amide, and some $\mathrm{NH}_{3}{ }^{+}$groups, with the nitrogen containing groups predominantly being produced by the $\mathrm{NH}_{3} / \mathrm{He}$ plasma.

The preliminary, qualitative adhesion tests showed that the epoxy resin very readily delaminates from the untreated GC surface, whereas on the samples plasma treated quasiuniformly for $5 \mathrm{~min}$ with either gas mixture, it was impossible to remove the epoxy cleanly using the blade.

Three DCB sandwich specimens were made for each of the three conditions applied in the above qualitative test. The specimens containing one untreated GC plate were very fragile, and two specimens, as well as a spare one, accidentally delaminated before they could be tested. Testing the one remaining we measured a critical energy release 
rate of $8 \mathrm{~J} / \mathrm{m}^{2}$. Regarding the plasma treated samples, the DCB test confirmed the result of the qualitative test. In all but one case for each plasma composition, the adhesive bond was so strong that cohesive failure of one or the other GC plate occurred when the crack reached the treated region. The critical energy release rate almost invariably increased monotonically as the crack propagated along the interface being tested. Although this apparent increase in fracture resistance may be an effect of toughening due to plasticity, ${ }^{16)}$ we think this behaviour is more likely to be an effect of the treatment effect not being completely localized to the area directly below the discharge plasma. This property of the treatment was confirmed by contact angle measurements.

For the two specimens that ultimately failed at the interface, the applied moment required for crack propagation in the last five cycles before failure was within $17 \%$ of that of the last cycle. Also, five cycles before failure, when observed in the optical microscope, the crack appeared to cross the boundary of the directly plasma treated zone at $32 \mathrm{~mm}$ from the sample end. The average of the corresponding energy release rates was adopted as the fracture energy of the respective adhesive bond. For the He treated surface this value was $100 \pm 8 \mathrm{~J} / \mathrm{m}^{2}$, whereas for $\mathrm{NH}_{3} / \mathrm{He}$ treatment it was $152 \pm 24 \mathrm{~J} / \mathrm{m}^{2}$. The trend of the $\mathrm{NH}_{3} / \mathrm{He}$ treatment being more effective was observed in the cohesively failing specimens as well: the energy release rates equivalent to the maximum moments resisted by these were $108 \mathrm{~J} / \mathrm{m}^{2}$ for $\mathrm{He}$ treatment and $210 \mathrm{~J} / \mathrm{m}^{2}$ for $\mathrm{NH}_{3} / \mathrm{He}$ treatment.

\section{Conclusions}

The effect of treating GC surfaces with cold atmospheric pressure $\mathrm{He}$ and $0.17 \% \mathrm{NH}_{3} / \mathrm{He}$ plasmas from a torch source was studied. The $\mathrm{NH}_{3} / \mathrm{He}$ plasma etched the surface approximately one order of magnitude faster than He plasma alone and at a rate comparable to low-pressure reactive ion etching. A substantial surface roughening resulted from the treatment. In addition, the water contact angle was dramatically reduced, as oxygen and nitrogen containing functional groups were introduced on the surface. The nature of these groups is somewhat uncertain, but likely to include carboxylic acid, ester, amide, and $\mathrm{NH}_{3}{ }^{+}$groups. A larger quantity of nitrogen containing groups was introduced when
$\mathrm{NH}_{3}$ was present in the discharge feed gas, whereas, when it was absent, oxygen was more abundant. This variation correlates well with the predominant observation of $\mathrm{NH}$ in the $\mathrm{NH}_{3} / \mathrm{He}$ plasma and of atomic oxygen and $\mathrm{OH}$ in the $\mathrm{He}$ plasma. The modification of the surface led to at least a 12fold increase in the adhesion energy of the GC to epoxy with pure He plasma treatment and at least a 19-fold increase with the $\mathrm{NH}_{3} / \mathrm{He}$ plasma treatment.

\section{Acknowledgements}

This work was supported by the Danish Technical Research Council (STVF, grant no. 26-04-0251). Lene Hubert and Jørgen Stubager are gratefully acknowledged for technical assistance.

1) Y. Qiu, X. Shao, C. Jensen, Y. J. Hwang, C. Zhang and M. G. McCord: in Polymer Surface Modification: Relevance to Adhesion, ed. K. L. Mittal (VSP, Utrecht, 2004) Vol. 3.

2) N. Inagaki, K. Narushim, N. Tuchida and K. Miyazak: J. Polym. Sci., Part B 42 (2004) 3727.

3) K. R. Kull, M. L. Steen and E. R. Fisher: J. Membr. Sci. 246 (2005) 203.

4) H. Koinuma, H. Ohkubo, T. Hashimoto, K. Inomata, T. Shiraishi, A. Miyanaga and S. Hayashi: Appl. Phys. Lett. 60 (1992) 816.

5) High Resolution XPS of Organic Polymers-The Scienta ESCA300 Database, ed. G. Beamson and D. Briggs (John Wiley \& Sons, Chichester, 1992).

6) B. F. Sørensen, A. Horsewell, O. Jørgensen, A. N. Kumar and P. Engbæk: J. Am. Ceram. Soc. 81 (1998) 661.

7) G. Bao, S. Ho, Z. Suo and B. Fan: Int. J. Solids Struct. 29 (1992) 1105.

8) Y. Yamagata, A. Sharma, J. Narayan, R. M. Mayo, J. W. Newman and K. Ebihara: J. Appl. Phys. 86 (1999) 4154.

9) Y. Yamagata, A. Sharma, J. Narayan, R. M. Mayo, J. W. Newman and K. Ebihara: J. Appl. Phys. 88 (2000) 6861.

10) M. Kuhnke, T. Lippert, E. Ortelli, G. G. Scherer and A. Wokaun: Thin Solid Films 453-454 (2004) 36.

11) M. Kuhnke, T. Lippert, G. G. Scherer and A. Wokaun: Surf. Coat. Technol. 200 (2005) 730.

12) L. E. Cruz-Barba, S. Manolache and F. Denes: Langmuir 18 (2002) 9393.

13) S. Biniak, G. Szymański, J. Siedlewski and A. Światkowski: Carbon 35 (1997) 1799.

14) Y. M. Xie and P. M. A. Sherwood: Appl. Spectrosc. 43 (1989) 1153.

15) R. Flamia, G. Lanza, A. M. Salvi, J. E. Castle and A. M. Tamburro: Biomacromolecules 6 (2005) 1299.

16) V. Tvergaard and J. W. Hutchinson: Philos. Mag. A 70 (1994) 641. 